\title{
Lexical and semantic access in Letter-by-Letter Dyslexia: A case report
}

\author{
Silvia Aggujaro, Davide Crepaldi, Enrico Ripamonti, Claudio Luzzatti \\ Department of Psychology, University of Milano-Bicocca
}

\section{Introduction}

Letter-by-letter (LBL) dyslexia is a reading impairment caused by left occipital damage and characterized by significant increase in reading time according to the number of letters in a given string (word length effect). In analogy to Dejerine's interpretation of pure alexia (1892), this disorder is said to be the consequence of a disconnection of the word-blind right hemisphere $(\mathrm{RH})$ from the left hemisphere (LH) word recognition system (angular gyrus). However, several patients have been found to maintain some reading capacities. Coslett \& Saffran (1989) described four LBL patients who performed better than chance either on lexical decision or on semantic judgment tasks with words that could not be explicitly identified (implicit reading). Results are controversial (Behrmann, Black \& Bub, 1990) and not consistent with the assumption of a complete RH blindness. Data on pure alexia and LBL reading were mostly obtained on French- or English-speaking patients, i.e. patients speaking languages with largely irregular orthography, but similar results were also occasionally reported for languages with shallow orthography, like Italian (Perri, Bartolomeo, \& Silveri, 1996). The purpose of the present study is to collect data on the nature of the implicit reading phenomenon, to analyze the explicit and implicit reading abilities of a bilingual English and Italian-speaking patient suffering from LBL dyslexia, and to verify for a possible different reading behavior in the two languages.

\section{Case History}

$\mathrm{CM}$ is a 63-year-old American English native speaker, who had lived in Italy for 30 years. She suffered from an ischemic cerebro-vascular attack in August 2003, which resulted in complete right-homonymous hemianopia and dramatic (almost pure) reading impairment. CM's spelling ability was only mildly impaired both in 
English and in Italian, with significant lexicality and length effect. The patient's reading abilities were first tested in detail in October 2003, both in English and in Italian.

\section{Experimental tasks}

\section{READING}

The patient was tested in Italian with a reading task of 61 words and 30 nonwords. English stimuli were 80 words and 24 nonwords (tasks 31 and 36 of the PALPA; Kay et al., 1996). Word length, imageability and word frequency were considered in both languages; the Italian task also included a set of function words. The reading performance was analyzed both for accuracy (time limit $=2$ seconds) and for speed. Patient's reading was slow and effortful, with a clear length effect (she often had to write with her finger on the desk to retrieve the letters' name). The pattern is consistent in both languages with a LBL reading impairment (see Table).

\section{English}

Accuracy. CM named correctly $28 \%$ of the items, with lexicality (55\% vs $17 \%$; $\left.\mathrm{Chi}^{2}=9.13 ; \mathrm{p}<.005\right)$ and strong imageability effect $\left(55 \%\right.$ vs $8 \% ; \mathrm{Chi}^{2}=14.52 ; \mathrm{p}<$. 001).

Reading Time. When responses were analyzed without a time limit, CM named correctly $89 \%$ of items; words were named more accurately than nonwords (93\% and $79 \%$ respectively), but the difference only approaches significance $\left(\mathrm{Chi}^{2}=3.47 ; \mathrm{p}=\right.$. 06). In accordance with the LBL reading behavior, the mean reading time is very long (8.0 seconds).

\section{Italian}

Accuracy. CM named only 3\% of the items within two seconds; this performance is significantly lower than that obtained in English $\left(\mathrm{Chi}^{2}=21.39 ; \mathrm{p}<.001\right)$.

Reading Time. When responses were analyzed without a time limit, CM named words more accurately than nonwords (97\% vs. 77\%; $\left.\mathrm{Chi}^{2}=9.07 ; \mathrm{p}<.01\right)$; no difference emerged for imageability, frequency and grammatical class. CM was very slow also in naming Italian stimuli (mean $=12.7$ seconds). 
CM was given a lexical decision task of words and nonwords. English stimuli were taken from the PALPA (task 25).

The exposure time of the letter strings (500 mseconds followed by a mask) was much shorter than the time required for an effective LBL reading strategy. English words were compared for imageability and word frequency; in Italian, words were also compared for grammatical class.

CM identified $97 \%$ of the English words, and rejected $65 \%$ of the English legal nonwords and $100 \%$ of the illegal nonwords $\left(\mathrm{Chi}^{2}=27.7 ; \mathrm{p}<.001\right)$. A similar pattern also emerged in the Italian task where she identified $79 \%$ of the words, and rejected $33 \%$ of legal nonwords and $100 \%$ of illegal nonwords $\left(\mathrm{Chi}^{2}=37.26 ; \mathrm{p}<.001\right)$. Italian function words were identified more poorly than concrete nouns (44\% vs. 94\%; $\mathrm{Chi}^{2}=$ $=14.89 ; \mathrm{p}<.001)$; a frequency effect is also observed in Italian $\left(92 \% \mathrm{vs} 69 \%\right.$; $\mathrm{Chi}^{2}=$ $5.67 ; \mathrm{p}<.05)$.

\section{SEMANTIC JUDGMENT TASK}

The patient was given a list of words and was asked to judge whether they belonged or not to a specific semantic category (animals, food, cloths); the procedures and the timeline of this task were identical to those used in the lexical decision task. CM misjudged only $5 \%$ of the English and $8 \%$ of the Italian items.

------- Table about here -------

\section{Discussion}

The patient's behavior during the reading tasks indicates that CM suffers from pure alexia with LBL reading strategy both in English and Italian. English reading within two seconds is characterized by lexicality and imageability effects, whereas the performance on the Italian task is severely impaired for all classes of items. Both in English and in Italian the performances obtained in the lexical decision and semantic judgment tasks unequivocally demonstrate that the patient could access her implicit lexical and conceptual knowledge, even in absence of any explicit word naming.

These findings are consistent with the assumption of residual $\mathrm{RH}$ reading 
abilities, which still allow for explicit reading of concrete words, but only in English. A different performance in English and Italian may be due either to independent reading procedures for native vs. second language or to different mechanisms underlying the reading performance in languages with irregular or with shallow orthographies; further evidence are required to disentangle these alternative hypotheses.

\section{References}

Behrmann, M., Black, S.E., Bub, D.N. (1990). The evolution of pure alexia: A longitudinal study of recovery. Brain and Language, 39, 405-427.

Coslett, B., Saffran, E.M. (1989). Evidence for preserved reading in "pure alexia". Brain, 112, 327-359.

Dejerine, J. (1982). Contributions à l'étude anatomo-pathologique et clinique de différentes variétés de cécité verbale. Comptes Rendus Hebdomadaires des. Séances et Mémoires de la Société de Biologie, Ninth series, 4, 61-90.

Kay, J., Lesser, R., Coltheart, M. (1996). Psycholinguistic assessments of language processing in aphasia (PALPA): An introduction. Aphasiology, 10, 159-180.

Perri, R., Bartolomeo, P., Silveri, M.C. (1996). Letter Dyslexia in a Letter-by-Letter Reader. Brain and Language, 53, 390-407. 
CORRESPONDING ADDRESS:

Silvia Aggujaro

Department of Psychology, University of Milano-Bicocca, piazza dell'Ateneo Nuovo 1, 20126, Milano, Italy.

E-mail: silvia.aggujaro@unimib.it 


\section{TABLE}

Patient's performance on the experimental tasks. Reading: Accuracy1 (\% correct, time limit $=2$ seconds); Accuracy2 (\% correct, no time limit); mean reaction time (seconds, no time limit); Lexical decision: Accuracy (\% acceptance of words, \% rejection of nonwords); Semantic judgments: Accuracy (\% correct).

\begin{tabular}{|c|c|c|c|c|c|c|c|c|c|}
\hline & & \multicolumn{4}{|c|}{ English } & \multicolumn{4}{|c|}{ Italian } \\
\hline & & $\mathrm{N}$ & Accuracy 1 & Accuracy2 & mean RT & $\mathrm{N}$ & Accuracy 1 A & Accuracy 2 & mean RT \\
\hline \multirow{7}{*}{ 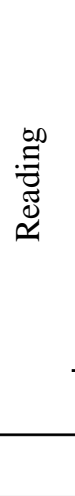 } & High imageability & 20 & 55 & 95 & 4.4 & 30 & 7 & 97 & 8.7 \\
\hline & Low imageability & 20 & 8 & 90 & 12.5 & 15 & 0 & 93 & 12.7 \\
\hline & High frequency & 20 & 30 & 98 & 7.1 & 31 & 10 & 93 & 9.2 \\
\hline & Low frequency & 20 & 32 & 88 & 9.2 & 30 & 0 & 100 & 11.2 \\
\hline & Function words & - & & & & 16 & 6 & 94 & 10.6 \\
\hline & Nonwords & 24 & 17 & 79 & 10.7 & 30 & 0 & 77 & 17.6 \\
\hline & & $\mathrm{N}$ & Accuracy & (Yes) Acc & uracy (No) & $\mathrm{N}$ & Accuracy (Yes) & Accur & racy (No) \\
\hline \multirow{8}{*}{ 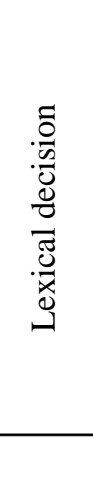 } & High imageability & 30 & 97 & & & 36 & 94 & & \\
\hline & Low imageability & 30 & 100 & & & 18 & 83 & & \\
\hline & High frequency & 30 & 100 & & & 36 & 92 & & \\
\hline & Low frequency & 30 & 97 & & & 36 & 69 & & \\
\hline & Function words & - & & & & 18 & 44 & & \\
\hline & Legal nonwords & 60 & & & 65 & 18 & & & 33 \\
\hline & Illegal nonwords & 15 & & & 100 & 18 & & & 100 \\
\hline & & $\mathrm{N}$ & Accuracy & (Yes) Acc & uracy (No) & $\mathrm{N}$ & Accuracy (Yes) & Accur & racy (No) \\
\hline \multirow{4}{*}{ 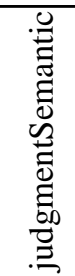 } & Animals/non-animals & $13+13$ & 92 & & 100 & $13+13$ & 92 & & 85 \\
\hline & Food / non-food & $13+13$ & 92 & & 100 & $13+13$ & 92 & & 100 \\
\hline & & & & & & $13+13$ & & & \\
\hline & Cloths / non-cloths & $13+13$ & 92 & & 92 & & 100 & & 85 \\
\hline
\end{tabular}

